\title{
INSERÇÃO E PARTICIPAÇÃO DE IMIGRANTES HAITIANOS EM UNIVERSIDADES BRASILEIRAS
}

\begin{abstract}
RESUMO: A migração é um fato social que consiste no entrar e no sair de indivíduos em um ou de um determinado espaço geográfico. A partir de 2010, o Brasil passou a ser o destino de milhares de haitianos em busca de melhores condições de vida, logo depois do desmoronamento do Haiti pelo terremoto de 12 de janeiro de 2010. A presença dos mesmos no território brasileiro gerou um fato imperativo para a inserção no mercado de trabalho e no ensino superior. Nesta perspectiva, este presente artigo possui como objetivo principal retraçar a migração haitiana, enfatizando a inserção e a participação de imigrantes haitianos em universidades brasileiras, especificamente a Universidade Federal da Fronteira Sul (UFFS), no campus de Chapecó, e na Universidade Federal da Integração Latino-Americana (UNILA).
\end{abstract}

PALAVRAS-CHAVE: Migração; Haiti; Brasil; Educação; Universidades.

\section{INSERTION AND PARTICIPATION OF HAITIAN IMMIGRANTS IN BRAZILIAN UNIVERSITIES}

\begin{abstract}
Migration is a social fact that consists of individuals entering and leaving a given geographic space. From 2010, Brazil became the destination of many Haitians in search of better living conditions, soon after the collapse of Haiti by the January 12, 2010 earthquake. Their presence in Brazilian territory generated the necessity of their insertion into the labor market and in higher education. In this perspective, this article has as main objective to retrace the Haitian migration, emphasizing the insertion and

${ }^{1}$ Graduando em Saúde Coletiva na Universidade Federal da Integração Latino-Americana. E-mail: wendyledix@yahoo.fr.
\end{abstract}


participation of Haitian immigrants in Brazilian universities, specifically in the Federal University Southern Border (UFFS), Chapecó campus, and the Federal University of Latin American Integration (UNILA).

KEYWORDS: Migration; Haiti; Brazil; Education; Universities.

\section{INTRODUÇÃO}

A República do Haiti, comumente chamada de Haiti, enfrenta muitos desafios em termos de planejamento socioeconômico e esforços para assegurar o crescimento econômico e a criação de empregos num contexto mundial de crise econômica. $\mathrm{Na}$ escala nacional, o contexto atual é o da alta vulnerabilidade ecológica, desequilíbrios sociais e comerciais e a falta geral de infraestrutura adequada, de energia sustentável e instituições suficientemente fortes para apoiar sua integração à economia mundial. Porém, da perspectiva de seus fluxos de emigração, o país já se encontra bem integrado ao sistema global.

No entanto, o Haiti é o primeiro país negro tanto a conquistar a abolição da escravidão no mundo por meio de uma revolta geral dos escravizados quanto a declarar independência. Esta antiga colônia francesa tem uma história bastante conturbada. Nela, 80\% da população vive abaixo da linha da pobreza e dois terços sobrevivem da pesca e da agricultura praticada em espaços erosivos, marcados pela superexploração, nos períodos das colonizações espanhola e francesa (SEGUY, 2010), e o desmatamento, restando $2 \%$ de áreas de florestas, em 2006. À precariedade das condições de produção e de vida somam-se problemas sociais decorrentes de conflitos políticos (CEOLIN, 2014).

Diante desta situação precária do país, um número significativo de haitianos encontrou-se na obrigação de sair do Haiti em direção a diversos cantos do mundo. Estudantes, professores, trabalhadores, funcionários públicos, desempregados, todos são sujeitos a ser migrantes. Para a Organização das Nações Unidas, o "migrante" é qualquer pessoa que vive, permanentemente ou temporariamente, num país no qual não nasceu e no qual criou relações. 
O Haiti, pela sua história, vem conhecendo uma forte migração. Um de seus fluxos mais recentes - além da migração haitiana rumo ao Chile - é voltado para o Brasil. Muitos deles vêm ao Brasil para trabalhar e estudar. O mercado de trabalho foi o campo mais explorado por eles, pois o Brasil sempre vem requerendo mão-de-obra barata. O que despertou as autoridades locais sobre a pertinência de se pensar uma forma de propiciar uma inserção viva dos imigrantes haitianos na educação foi pela simples hipótese de que muitos deles estudavam no Haiti, mas, chegando aqui, não teriam como continuar seus estudos.

Tendo em vista o exposto, este artigo possui como objetivo principal retraçar a migração haitiana, enfatizando a inserção e a participação de imigrantes haitianos em universidades brasileiras, especificamente na Universidade Federal da Fronteira Sul (UFFS), no campus de Chapecó, e na Universidade Federal da Integração Latino-Americana (UNILA).

\section{METODOLOGIA}

O estudo aqui apresentado é de natureza quantitativa e qualitativa e busca contribuir para: apresentar as linhas gerais da história da migração haitiana, ainda que sem uma análise de suas causas mais profundas; além disso, informar de que forma está sendo feita a inserção de imigrantes haitianos no ensino superior no Brasil, especialmente em duas universidades federais, a saber, a Universidade Federal da Fronteira Sul (UFFS) e a Universidade Federal da Integração Latino-Americana (UNILA); e, por fim, mostrar como esses imigrantes estão participando no tripé da universidade: ensino-pesquisa-extensão.

Oriundo de uma observação empírica, o estudo foi feito pelas seguintes perguntas de pesquisa: Com que sentimento você deixou o Haiti? O que fez você migrar para o Brasil? Como foi a adaptação no meio universitário? Você já pensou em abandonar tudo e voltar definitivamente para o seu país? Como você encara o desafio de ser estudante num país estrangeiro? Você recebe alguns auxílios por parte da Universidade? Você participa em alguns projetos de extensão e/ou pesquisa? 
A vinda dos Haitianos para o Brasil tem sido considerada como sendo a maior onda migratória ao país em cem anos, comparada historicamente àquela de italianos e japoneses que aportaram no país ainda no período imperial e nos primeiros anos da República (FOLHA, 2012). Este fato gerou uma redefinição de políticas públicas em termos de acolhimento. Assim surgiu o Pró-Haiti, programa de inserção de haitianos em universidades brasileiras.

A coleta de dados ocorreu no mês de julho/2017, por meio da aplicação de um questionário semiestruturado; também por meio de fontes relacionadas ao assunto de estudo (livros, artigos, documentários, entre outros); e por meio de uma observação de campo feita através de uma observação participante.

De acordo com Demo (2000, p.21), a observação participante é intrínseca à prática, pois há nela um fundamento que possibilita discutir a importância do processo de investigação tendo por perspectiva a intervenção na realidade social. Segundo esse autor, a pesquisa prática é ligada à práxis, ou seja, à prática histórica em termos de usar conhecimento científico para fins explícitos de intervenção; nesse sentido, não esconde sua ideologia, sem com isso necessariamente perder de vista o rigor metodológico.

Após a coleta, os dados foram analisados buscando garantir o sigilo, sem mencionar os nomes dos participantes. Nesta pesquisa, participaram seis estudantes do campus de Chapecó da UFFS, repartidos em vários cursos, tais como: Agronomia, Engenharia Ambiental e Sanitária, Filosofia e Matemática; e dezenove estudantes da UNILA, matriculados nos seguintes cursos: Administração Pública e Políticas Públicas, Biotecnologia, Ciências Biológicas, Ciências Econômicas, Cinema e Audiovisual, Desenvolvimento Rural e Segurança Alimentar, Engenharia Física, Engenharia Química, História- América-latina, Letras, Relações Internacionais e Integração, Saúde Coletiva e Serviço Social. 


\section{HISTÓRIADA MIGRAÇÃO NO HAITI}

\section{ÉPOCA COLONIAL}

A migração haitiana, em contexto nenhum, pode ser considerada como algo recente, já que o povoamento da ilha do Haiti começou em 4000 a.C. com migrações sucessivas da América Central ou da Península de Iucatã de um grupo cuja presença dominou a ilha durante um intervalo de tempo de, aproximadamente, três milênios, até cerca de 400 a.C. Esta cultura, chamada Casimiroide, misturou-se à cultura cerâmica, agrícola e sedentária dos Saladoides que migrara da América do Sul e que, rapidamente, colonizaram as ilhas do arquipélago, estabelecendo sua presença nas ilhas de Porto Rico e Hispaniola ${ }^{2}$ por volta de 400 a.C.. Esta história continua com os povos Taino/Arawak, que pertenciam igualmente à cultura Saladoide e que ocuparam o espaço desenvolvendo instalações agrícolas sedentárias para quase dois milênios (REID, 2009).

As sucessivas invasões em 1492 acabaram com esta civilização na ilha do Haiti com a remoção pela escravidão, a propagação de doenças e massacres durante quatro décadas de guerra que seguiram-se ao estabelecimento da escravidão americana nativa. Este ano é marcado pela invasão da tropa espanhola, liderada por Cristóvão Colombo. Os espanhóis ocuparam a ilha do Haiti por 205 anos (1492-1697). Os povos que ali viviam foram submetidos a trabalhos forçados sob o comando dos invasores e não resistiram. Com a chegada dos espanhóis, o genocídio de quatro quintos da população nativa no Haiti, estimada entre 1,5 e 2 milhões de habitantes (LAURENT COPA, 1993, p.25), marcou o início da utilização da ilha como uma colônia de exploração e foi acompanhado e seguido pelo início da importação de cativos africanos a partir de 1503. Assim, começou o tráfico negreiro para a ilha.

No século XVII, corsários franceses começaram a se estabelecer na ilha vizinha de "LaTortue", território que pertence à República do Haiti. Chamam-se pomposamente de "Irmãos da costa." Eles eram caçadores, estimados em 3.000 indivíduos, e foram também piratas e corsários

${ }^{2}$ Nome dado à ilha do Haiti pelos invasores espanhóis, que significa "Pequena Espanha". 
predando galeões espanhóis. Em agosto de 1640, os corsários franceses expulsaram os seus rivais ingleses que ali tinham invadido e desembarcaram no norte da ilha de Hispaniola.

No meio das brigas entre os diferentes invasores, em 1697, a Espanha legalmente cedeu à França a parte ocidental de Hispaniola (atualmente conhecida como Haiti), o que ficou registrado no Tratado de Ryswicke ${ }^{3}$, que pôs fim à Guerra da Liga de Augsburg. Esta aquisição marca o verdadeiro início das ambições coloniais da França, que colonizou o país por 106 anos (1697-1803), fortalecendo a mão-de-obra escrava com o tráfico negreiro.

Esta atividade de tráfico de cativos africanos durou cerca de 150 anos. De acordo com a lógica do Código Negro ${ }^{4}$, a população da ilha do Haiti em 1780 foi estimada da seguinte forma: 450.000 escravos, 28.000 mulatos (pessoas nascido de grupos europeus e africanos étnicos) e negros livres, 30.000 brancos (WARGNY, 2008, p. 31). A extensão massiva do fluxo migratório rumo à ilha atingiu uma estimativa de 800.000 cativos africanos entre 1680 e 1786. A economia do Haiti era completamente orientada para o exterior e exportava produtos destinados à elaboração secundária e ao consumo. A importação de Negros advindos de vários lugares da África também fazia parte de um sistema de criação de riqueza colonial e imperial da época. No final de seu período como colônia francesa, em 1791, a população de escravos do Haiti chegou a 500.000 habitantes.

\section{NA AURORA DA REPÚBLICA DO HAITI}

A imigração de cativos africanos para a ilha foi definitivamente interrompida com a Revolução Haitiana (1791-1804). Contudo, os líderes

\footnotetext{
${ }^{3}$ O Tratado de Ryswick gerou a cisão da ilha do Haiti em República do Haiti que representa um terço do território, sob o controle da França e da República Dominicana - que, por sua vez, representa os dois terços sob o controle da Espanha. É esse ato jurídico e histórico que justifica o porquê de se falar francês na República do Haiti e espanhol na República Dominicana.

${ }^{4}$ O Código negro é um documento no qual o legislador finge considerar a humanidade do escravo negro, apresentando-o, do ponto de vista jurídico, como uma mercadoria submetida às leis do mercado e ao desejo do seu dono.
} 
da nova República do Haiti imediatamente começaram uma política de atração de mão-de-obra para o país. O imperador Jean-Jacques I (JeanJacques Dessalines), o primeiro presidente do Haiti, recrutou cidadãos da República vizinha dos Estados Unidos da América, oferecendo recompensas aos capitães marítimos para facilitar a chegada de negros norte-americanos ao Haiti (ALEXANDER, 2013, p. 199). A definição de uma política migratória de incentivo à imigração continuou sob os regimes contemporâneos do Rei Henri Christophe e Presidente Alexandre Pétion:

Esse país chamado de Haiti, e por favor chame-o por seu nome Haiti e não outra coisa que você ouve outras pessoas chamando. Essa é uma terra que os fundadores definiram que seria o refúgio para todas as pessoas negras do mundo. [...] Não é a propriedade do pequeno grupo que estava ali, mas a visão deles era a seguinte: nós vamos criar um espaço aqui, um espaço onde qualquer pessoa negra fugindo de qualquer tipo de estrago opressivo, qualquer caos opressivo, ela pode vir aqui e instantaneamente qualquer pessoa negra que pisar os pés nessa terra se tornará automaticamente livre e um cidadão...(relato de Bayyinah Bello, professora e historiadora).

O regime do Pétion, terceiro presidente do Haiti, produziu a Constituição revisada de 1806, e o artigo 44 permitiu a concessão da cidadania haitiana a pessoas de origem africana ou indígena que tivessem vivido no Haiti por pelo menos um ano. $\mathrm{O}$ artigo também afirma que essas pessoas são automaticamente consideradas cidadãs haitianas até que se mudem do país, fazendo com que a concessão de cidadania permaneça condicional. O objetivo desta iniciativa era estender as liberdades conquistadas durante a Revolução Haitiana, além de beneficiar a economia haitiana através do acesso à mão de obra qualificada (ALEXANDER, 2013, p. 199).

A resposta entre a população negra dos Estados Unidos da América foi afirmativa e a criação de Haitian Emigration Societies (Sociedades de Emigração Haitiana) foi iniciada em cidades como Nova Iorque, Boston, 
Filadélfia e Baltimore. A chegada ao poder do presidente Jean Pierre Boyer e a reunificação posterior da República do Haiti conheceram a implementação de um programa acelerado de recrutamento. A abordagem do presidente Boyer incluiu uma campanha de recrutamento ativo nos Estados Unidos, em parceria com instituições religiosas afro-americanas, e também o investimento financeiro na facilitação da mobilidade de pessoasalvo. A política migratória de Boyer, que incluía concessões de terras e subsídios para o transporte de imigrantes, considerava o desenvolvimento econômico por meio da importação de mão-de-obra qualificada e a possibilidade de uma reaproximação com os Estados Unidos da América e os benefícios potenciais do reconhecimento do Haiti por Washington para as relações comerciais e diplomáticas.

\section{MIGRAÇÃO NO SÉCULO XX}

O final da década de 1880 foi marcado pela criação de condições econômicas, políticas e tecnológicas propícias para o surgimento da empresa multinacional moderna. No Caribe, a aquisição de terras produtivas por empresas britânicas, como Tate e Lyle e empresas americanas como United Fruit Company permitiram a organização da produção (açúcar, café, bananas) numa escala sem precedente. $\mathrm{O}$ deslocamento dos agricultores de suas terras era uma prática muito conhecida na região (HEADLY, 1996) e contribuiu para a conversão da economia de subsistência agrícola numa economia de trabalhadores independentes à procura de emprego, especialmente pela migração para grandes cidades ou para outros países da região.

Com a construção do Canal do Panamá,surgiram práticas de recrutamento por agências governamentais norte-americanas, além de também empresas multinacionais de trabalhadores (especialmente homens) do Caribe para trabalhar não somente na construção deste, mas também em plantações agrícolas da América Central e afora a partir de 1904 (RICHARDSON, 1985, p.105-107). Concluída em 1914, a construção de Canal também destacou a importância estratégica das 
Ilhas de trânsito da América Central para os Estados Unidos. O governo dos EUA, que havia,desde 1898, começado a consolidar sua influência geopolítica na região com a ocupação de várias ilhas, incluindo Cuba e Porto Rico, invadiu o Haiti e a República Dominicana em 1915 e 1916, respectivamente (PETRAS, 1988, p.127; BULMER-THOMAS, 2001, p. 6). Assim, teve início a ocupação americana no Haiti, reforçada pela doutrina de Monroe: "A América aos [Nortes] Americanos". No Haiti, esta durou cerca de 19 anos (1915-1934).

Durante este período, milhares de camponeses, expropriados pelo invasor e submetidos à labuta, emigraram como cortadores de cana nos canaviais americanos da República Dominicana e de Cuba. A situação piorou tanto que, em 1937, ou seja, dois anos depois da ocupação, a burguesia dominicana havia organizado o massacre de mais de 30 mil trabalhadores haitianos, com a cumplicidade da burguesia haitiana. O racismo da ultradireita dominicana, como foi demonstrado através da Sentença No. 168-13 do Tribunal Constitucional, alimentava constantemente o temor de que a presença haitiana não se revelasse demasiado significativa em termos quantitativos na República Dominicana.

Em torno dos anos 1950, registrou-se cerca de 19.000 haitianos ainda presentes na República Dominicana, mas a partir de 1964, a população haitiana aumentou consideravelmente para 60.000 e, em 1970, 300.000 habitantes. Nos Estados-Unidos, mesmo para os anos 50, a presença haitiana foi praticamente insignificante. Para os anos 60 e 70, os trabalhadores imigrantes haitianos chegaram até 200.000 , mas os serviços da imigração não puderam mais controlar as chegadas.

A convergência da consolidação da influência geopolítica estadunidense e a expansão da produção multinacional agrícola teve ramificações importantes para os fluxos migratórios no Haiti. A ocupação americana foi acompanhada pelo aprofundamento da centralização da educação e do poder administrativo. A desmontagem da produção camponesa também foi realizada em outras ilhas da região. No entanto, o confisco e a apropriação de terras produtivas por empresas e investidores americanos nas áreas designadas como rurais causaram um êxodo rural para as grandes cidades e também para a República Dominicana e Cuba 
(também ocupados por forças norte-americanas) (WARGNY, 2008, p. 63). De fato, esta dotação feita pela repressão e expulsões forçadas foi acompanhada de recrutamento de mão-de-obra haitiana para as plantações de açúcar dos estadunidenses na República Dominicana (FATTON, 2014, p. 61-62).

Neste período de intensa mudança econômica, então, o país já mostrou duas das três principais tendências atuais, ou seja, migração interna, das áreas rurais para as grandes cidades e particularmente a capital do país, Port-au-Prince, e a emigração de trabalhadores para os países vizinhos do Haiti, especialmente Cuba e República Dominicana. No entanto, além do deslocamento da comunidade germano-haitiana durante a invasão americana, o êxodo de força de trabalho altamente qualificada e estudantes de nível superior para as metrópoles nortesamericanas e a Europa não era ainda notável. Como o afirma Olibri (2014, p. 24):

Antes da primeira ocupação americana do país (1915-1934), havia alguns haitianos oriundos especialmente da pequena burguesia urbana, que podia pagar-se o luxo de mudar para os Estados Unidos, a França ou as colônias britânicas do Caribe, seja para estudos ou para escapar das turbulências políticas internas; mas isto não era suficientemente desenvolvido a ponto de afetar a economia do país. A evolução da formação social do país vai causar uma espécie de inclinação; no sentido de que diferentes fatores (sociais, econômicos e políticos) iam combinar-se para transformar grande parte da população em potenciais migrantes. O que faz com que, com o passar do tempo, de certo modo, todos os estratos da sociedade vêm sendo mais ou menos envolvidos com a questão da migração.

Com o fim da ocupação americana, o Haiti continuou a experimentar a fuga generalizada das áreas rurais para a capital. Esta tendência foi acompanhada pelo crescimento da população devido ao declínio da mortalidade e ao aumento da taxa de natalidade no país. A migração rumo 
a Cuba também persistiu até a Revolução Cubana em 1959. Na República Dominicana, o recrutamento de trabalhadores continuou com o acordo bilateral entre o Haiti e a República Dominicana para a exportação de cerca de 16.500 trabalhadores haitianos em 1952 (VEGA, 1988, p. 272).

A República do Haiti participou de pleno direito à fundação da organização das Nações Unidas após a Segunda Guerra Mundial. Tendo adotado a Declaração Universal dos Direitos Humanos, em 1948, o país promulgou devidamente uma nova Constituição em 1950 que seguiu o sentido da Declaração confirmando, entre outros, o direito dos cidadãos haitianos de votarem, de participarem na direção dos negócios públicos e de acessarem aos serviços públicos. Princípios estes que seriam derrotados com a chegada ao poder do presidente ditador François Duvalier. A ditadura assinalou uma ruptura quase imediata com as considerações da Declaração Universal dos Direitos Humanos, exemplificada pela revogação do artigo $9^{5}$ da Declaração com a renovação do acordo bilateral entre o Haiti e a República Dominicana para a exportação de mão-de-obra haitiana em 1959. Este instrumento continuou servindo de ferramenta financeira importante do regime do F. Duvalier e o do seu filho, Presidente Jean-Claude Duvalier até seu exílio em 1986 (FATTON, 2014, p. 64-65).

O uso do pretexto do anticomunismo e a exploração das diferenças históricas de classe e cor na sociedade haitiana acarretaram um período de repressão política e social onde, segundo Olibri (2014), um número impressionante de haitianos da burguesia tradicional, da burguesia urbana, intelectuais da classe média (professores, médicos, engenheiros), vão fugir o país. Uma boa parte instalou-se nos centros metropolitanos nas regiões francófonas da África Ocidental e Canadá, o Nordeste dos Estados Unidos e a França (OLIBRI, 2014). Bellegarde-Smith (2013, p. 274) estima que a maior parte da classe profissional do país (aproximadamente $80 \%$ ) já havia se exilado na primeira década do regime do presidente ditador F. Duvalier.

Levando em consideração essa fuga dos haitianos rumo a diversos cantos do mundo, alguns autores passaram a se preocupar pelo assunto

\footnotetext{
${ }^{5} \mathrm{O}$ artigo 9 da declaração Universal dos Direitos Humanos estipula que ninguém pode ser arbitrariamente preso, detido ou exilado.
} 
a fim de tratá-lo. É exatamente nesta perspectiva que Georges Anglade ${ }^{6}$ apresentou numa figura, ainda em 2005, a repartição dos haitianos no mundo:

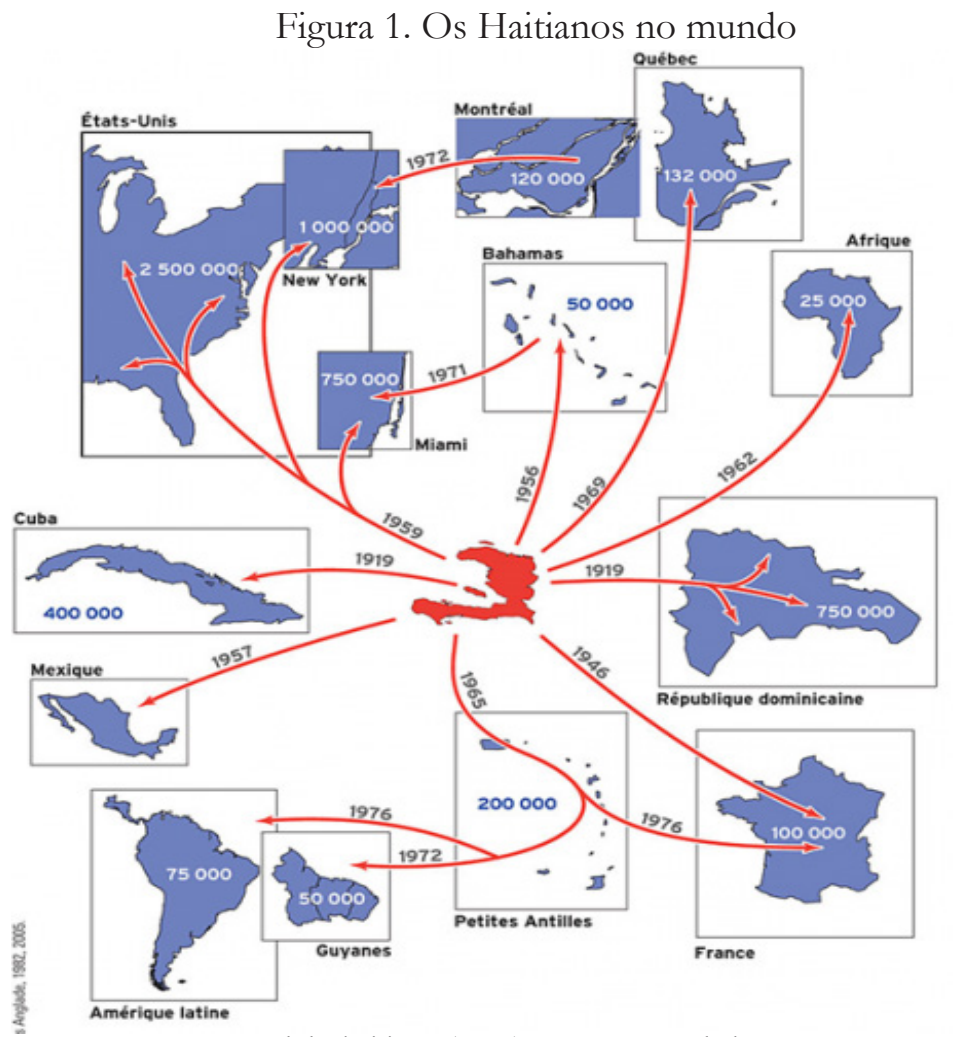

Fonte: www.canalplushaiti.net (2012); Georges Anglade, 1982, 2005.

${ }^{6}$ Nascido em Porto Príncipe (capital do Haiti) em 1944, foi estudar geografia aplicada em Strasbourg-Franca em 1965, e em seguida no Canadá em 1969. Georges Anglade foi um dos fundadores da Universidade do Quebec em Montreal (UQAM), onde ensinou a geografia social até 2002. Rebelde da ditadura militar, ele foi preso, exilado e ameaçado de morte várias vezes. Porta-voz do Movimento Haitiano de Solidariedade em 1986, autor do manifesto "la Chance que passe" (a Sorte que passa) em 1990, ele foi igualmente conselheiro dos presidentes Jean-Bertrand Aristid e René Préval até 1996 (Grégoire, 2012). Autor de numerosos livros consagrados à sua ilha natal, tais como "Mon pays d'Haiti”"(1997), "Espace de liberté en Haiti”'(1982) e "Ce pays m'babite"(2002), Georges morreu junto com a sua esposa Mireille no terremoto que, violentamente, abalou o Haiti no dia 12 de janeiro de 2010. 
Este êxodo não se realizou apenas do Haiti para outros países. Deu-se igualmente dentro do próprio país. Os campesinos e/ou citadinos passaram a migrar para a capital do país (Porto Príncipe) em busca de emprego. Por exemplo, "Em 1970, previa-se para 1972 um aumento de $15,8 \%$ da população de Porto Príncipe, e que chegaria a uma taxa recorde de $20 \%$, somente em 1982. Ora, este limiar foi atingido já desde 1971" (HURBON, op. cit. p. 29). Evidenciou-se assim que a urbanização, no país, se deu de forma anárquica, sem planejamento. É dali que se explicam as pesadas construções anárquicas que se observam em Porto Príncipe. A vulnerabilidade dos citadinos de Porto Príncipe aos desastres ecológicos e sanitários já em pauta nos anos de 1940 (TOBIN, 2013), tem sido exacerbada sob o regime dos Duvalier, assim criando as condições para a perda massiva de vida e consequentemente a tragédia que foi o resultado, em 12 de janeiro de 2010, da ocorrência do terremoto.

\section{O CENÁRIO PÓS-TERREMOTO}

O dia 12 de janeiro de 2010 marcou a história do Haiti e a vida de todos os haitianos, tanto os que permaneceram no país quanto aqueles na diáspora. $\mathrm{O}$ terrível terremoto que desabou o país nesta data expôs vivamente ao mundo inteiro a miséria cotidiana que o reprimia há séculos. Diante desse terror, numerosos resgatados decidiram deixar o país em direção ao Brasil. Com sentimentos distintos, muitos foram obrigados a partir:

Eu deixei meu país com uma mistura de vários sentimentos: tristeza, pois eu nunca pensei em viajar para ficar longe da família durante todo esse tempo, mas deixei-os com pouca alegria, pois sei que meus projetos vão continuar, isto é o prolongamento dos meus estudos superiores (UFFS, 2013, p. 2).

Eu migrei para o Brasil na ótica de poder dar continuidade aos meus estudos superiores e ao mesmo tempo poder trabalhar (UNILA, 2014, p. 17). 
O povo haitiano tem uma afinidade extrema pelo Brasil. O futebol e o carnaval representam as referências. A identidade cultural entre Brasil e Haiti trouxe uma certa dose de familiaridade. Em ambos os países houve a colonização de exploração, a existência de indígenas nos primórdios, o comércio de cana-de-açúcar, os imigrantes como sustento do povoamento que caracterizou a miscigenação, tanto por europeus, quanto por africanos, que, no dizer de Darcy Ribeiro (2014), seriam povos "transplantados". Posteriormente, as relações foram ainda mais veementes, com a visita de Pelé, da seleção brasileira de futebol e do ex-Presidente Lula no Haiti (HANDERSON, 2015). A presença da MINUSTAH ${ }^{7}$ no Haiti, liderada pela tropa brasileira, ajudou bastante nesta aproximação.

Assim, meses depois da tragédia, chegou um primeiro grupo de haitianos ilegais no Acre, usando a seguinte rota: Haiti-República Dominicana-Equador-Peru-Brasil. Alguns nem sequer passaram pela República Dominicana, pois com o visto dominicano, é possível entrar no Equador. Para frear esse fluxo ilegal, o Brasil ampliou a emissão de vistos pelas embaixadas em Porto Príncipe (Haiti), Quito (Equador) e Lima (Peru). Em 2015, houve uma queda de 96\% no número de haitianos ilegais que chegaram ao Brasil pelo estado.

Em quatro anos, foram emitidos 38.065 vistos permanentes para haitianos pelas embaixadas do Brasil - 30.385 em Porto Príncipe, 7.655 em Quito, e 25 em Lima, segundo o Itamaraty. Enquanto em 2012 foram emitidos 1.255 vistos, em 2015 o número saltou para 20.548. Dados da Divisão de Imigração do Ministério das Relações Exteriores (Itamaraty) apontam que a emissão de vistos a haitianos subiu 1.537\% de 2012 a 2015. Isso mostra que os imigrantes têm entrado no país regularizados por capitais como São Paulo e Rio de Janeiro, em vez de fazer a longa e cara viagem para entrar ilegalmente pelo Acre.

\footnotetext{
${ }^{7}$ A Missão das Nações Unidas para Estabilização do Haiti (MINUSTAH) foi criada por Resolução do Conselho de Segurança da ONU, em fevereiro 2004, para restabelecer a segurança e normalidade institucional do país após sucessivos episódios de turbulência política e violência, que culminaram com a partida do então presidente, Jean Bertrand Aristide, para o exílio. O Brasil sempre comandou o componente militar da Missão (2004-2017), que teve a participação de tropas de outros 15 países, além do efetivo brasileiro de capacetes azuis da Marinha, do Exército e da Força Aérea (Ministério da Defesa).
} 
Mesmo com essa estratégia da parte do Brasil, a erradicação da migração ilegal não foi possível, pois o processo para conseguir o visto nas embaixadas citadas acima demorava bastante. A partir de Quito, chegar à fronteira com o Peru pode levar dois dias ou mais, caso seja necessário esperar por um número maior de pessoas para realizar a viagem em grupo. Assim, a rota é percorrida desde que se tenha reunido o número suficiente de pessoas ou se acumulado o montante de dinheiro necessário. $\mathrm{O}$ visto de entrada no Peru é cobrado dos haitianos desde 25 de janeiro de 2012, medida que tornou muito difícil, caro e perigoso o deslocamento regular deles por este país. Logo, o trânsito pelo território peruano é organizado por redes de tráfico de pessoas, que adotam rotas e caminhos não oficiais para passagens dos imigrantes.

Diante das dificuldades de acesso ao visto de imigração temporária como turista no Peru, ampliou-se a vulnerabilidade dos haitianos durante a passagem pelo país andino, sendo inúmeros os relatos deles referentes à extorsão, violência e medo. Nesse circuito, onde eles dependem das redes de tráfico e seus coiotes para realizar a passagem pelo território peruano, driblando ou negociando com a fiscalização das fronteiras, os haitianos guardam na memória especialmente os abusos sistemáticos sofridos por parte de agentes policiais e civis peruanos.

Em relatos mais pontuais sobre a viagem, imigrantes lembram que nesse trecho muitos se tornam vítimas de roubo, cárcere, espancamentos, estupros e até mortes, situação que é agravada pelo desconhecimento da rota, do idioma local e especialmente pela condição de indocumentados.

Deixei o Haiti no dia 26 de maio do ano 2015 cheguei ao Panamá no mesmo dia, no dia seguinte fui pro Equador. Passei quatro dias em vários ônibus partindo do Equador para o Peru e do Peru até chegar no Brasil. A rota era muito arriscada porque não era uma passagem legal, fiz parte um grupo de pessoas que estavam sob a responsabilidade de uma rede de traficantes de seres humanos UFFS, 2013, p. 3). 


\section{A INSERÇÃO DOS HAITIANOS NO ENSINO SUPERIOR}

O Brasil e o Haiti mantêm relações diplomáticas desde 1928 (ano em que foram estabelecidas ligações entre ambos países), apesar de elas terem se tornado mais evidentes a partir de 2010, com o terremoto. Ocorre que, a partir de 2010, com o fluxo migratório de haitianos para o Brasil, as relações ganham novas perspectivas e exigências. Uma delas foi a vigência do Acordo Básico de Cooperação Técnica e Científica, firmado em 15 de outubro de 1982, e que somente entraria em vigor em novembro de 2004, através do Decreto no. 5.2848 (DIEME, 2016).

Ademais, anteriormente, mais especificamente em 05 de julho de 1966, a relação bilateral entre os dois países se deu com a assinatura do Convênio de Intercâmbio Cultural entre os Estados Unidos do Brasil e a República do Haiti, o qual, no artigo III, previu a concessão de bolsas de estudo, ipsis literis:

Convênio de Intercâmbio Cultural entre os Estados Unidos do Brasil e a República do Haiti, 05/07/1966

Artigo III - Cada Parte Contratante considerará a possibilidade de conceder anualmente bolsas de estudo a estudantes pós-graduados, profissionais liberais, técnicos, cientistas ou artistas, enviados por um país ao outro para aperfeiçoarem seus conhecimentos.

2. Aos brasileiros e haitianos, beneficiários dessas bolsas, será concedida dispensa de quaisquer taxas escolares.

Tendo em vista estas normas legais, em 25 de fevereiro de 2010, ocasião em que o Presidente Lula visita o Haiti, essa relação bilateral entre ambos se consolida ainda mais, com o "Memorando de entendimento entre o Governo da República Federativa do Brasil e o Governo da

\footnotetext{
${ }^{8}$ Decreto $^{\circ} 5.284 / 2004$

Artigo III - A cooperação a ser promovida pelas Partes Contratantes na implementação deste Acordo poderá abranger, entre outras, as seguintes modalidades: (...) b) promoção de programas de formação e aperfeiçoamento, através de cursos ou estágios específicos, de recursos humanos.
} 
República do Haiti para a reconstrução, o fortalecimento e a recomposição do Sistema de Educação Superior do Haiti"'.

Deste modo, a Portaria no 092/2010, editada pela Coordenação de Aperfeiçoamento de Pessoal de Nível Superior (CAPES) e publicada no Diário Oficial da União em 29 de abril de 2010, entrou em vigor na data da publicação e criou o Programa Emergencial Pró-Haiti em Educação Superior, dispondo de regras gerais para implementação de atividades relacionadas à prestação de auxílio às universidades haitianas, como também de concessão de bolsas de estudo para estudantes que já são universitários no Haiti estudarem no Brasil, na modalidade sanduíche.

A Universidade Estadual de Campinas (Unicamp) implementou o Pró-Haiti em 2011, nos moldes preconizados pela Portaria da Capes. Os estudantes saem do Haiti rumo ao Brasil, a fim de fazer graduação ou pós-graduação sanduíche em áreas distintas, recebem bolsa no valor que pode variar de $\mathrm{R} \$ 830,00$ a $\mathrm{R} \$ 1.500,00$, a depender do curso, durante os 18 meses de duração (MARINO, 2016).

Logo depois, outras universidades, tais como a Universidade Federal de Santa Catarina (UFSC) (Resolução Normativa nº 27/Cun/2012), a Universidade Federal de São Carlos (UFSCar) e a Universidade Federal do Rio Grande do Sul (UFRGS) iriam seguir o mesmo modelo da Unicamp.

Se, por um lado, o Pró-Haiti abre espaço para estudantes do Haiti virem para o Brasil para continuar estudando, por outro, ele só admite haitianos residindo no Brasil, que já têm o ensino médio completo e que não têm curso superior para ingressarem cursos de graduação. Tal é o caso da UFFS e da UNILA.

\footnotetext{
${ }^{9}$ Memorando de entendimento entre o Governo da República Federativa do Brasil e o Governo da República do Haiti para a reconstrução, o fortalecimento e a recomposição do Sistema de Educação Superior do Haiti, 25/02/2010.
} 


\section{NA UFFS (CAMPI CHAPECÓ)}

A Universidade Federal da Fronteira Sul (UFFS) é uma instituição de ensino superior pública, criada pela lei no 12.029, de 15 de setembro de 2009. Ela abrange mais de 400 municípios da Mesorregião Grande Fronteira Mercosul - Sudoeste do Paraná, Oeste de Santa Catarina e Noroeste do Rio Grande do Sul. O seu processo de criação começou com cinco campi: Chapecó (SC) - sede da instituição, Realeza e Laranjeiras do Sul (PR), e Cerro Largo e Erechim (RS). Recentemente a cidade de Passo Fundo também passou a receber um campus.

Com a Resolução No 32/2013 - CONSUNI, que institui o Programa de Acesso à Educação Superior da UFFS para estudantes haitianos, atendendo também à Resolução Normativa No 97, de 12 de janeiro de 2012, do Conselho Nacional de Imigração, que dispõe sobre a concessão de visto permanente por razões humanitárias a nacionais do Haiti, e à Lei no 13.445, de 24 de maio de 2017, que institui a Lei de Migração, a UFFS tornou-se um espaço que vem acolhendo haitianos que têm o ensino médio completo em diversos cursos de graduação, tais como Administração, Agronomia, Ciência da Computação, Ciências Sociais, Engenharia Ambiental, Filosofia, Geografia, História, Letras: Português e Espanhol, Matemática, Pedagogia etc.

As inscrições são feitas na Secretaria Acadêmica do campus, seja pessoalmente, por procuração simples ou por e-mail com opção de

Artigo 3 - Objetivos

O presente Memorando de Entendimento tem como objetivos:

a) Criar mecanismos para o envio de pesquisadores brasileiros ao Haiti com vistas a apresentar diagnósticos da situação das instituições de ensino superior do país;

b) Possibilitar a implementação de programa de graduação sanduíche para estudantes haitianos em instituições de ensino superior brasileiras;

c) Apoiar os cursos de português para estrangeiros nas universidades brasileiras, por meio de concessão de recursos de custeio;

d) Conceder bolsas de mestrado e de doutorado, nos moldes do Programa Estudante Convênio - PEC-PG, para estudantes haitianos;

e) Contribuir para a reestruturação das instituições de ensino superior haitianas por meio do envio de professores brasileiros em nível de pós-doutorado para ministrar aulas nas universidades e realizar seminários e missões de diagnóstico. 
confirmação de leitura. Para isso, é preciso que o(a) candidato(a) apresente certos documentos, tais como: Requerimento de inscrição preenchido e assinado, passaporte com visto vigente, cadastro de pessoa física $(\mathrm{CPF})$, cédula de identidade de estrangeiro, comprovante de residência e comprovação de conclusão do ensino médio. Uma vez feita a inscrição, o candidato terá que fazer uma prova de redação, em caráter eliminatório, e uma prova com algumas perguntas de múltipla escolha, para avaliar os conhecimentos do(a) candidato(a) em Língua Portuguesa, em caráter eliminatório.

A efetividade deste programa leva em consideração vários pontos cruciais, tais como: $\mathrm{O}$ esforço brasileiro para apoiar a reconstrução do Haiti; a decisão do Conselho Nacional de Imigração de conceder visto permanente por razões humanitárias a cidadãos Haitianos; a comunidade haitiana existente na região de abrangência da UFFS, em especial do campus de Chapecó; interesse da UFFS na proteção dos direitos humanos; e a importância de promover o intercâmbio e integração cultural entre estudantes haitianos e brasileiros no contexto da UFFS.

A Universidade oferece auxílios para a permanência dos ingressantes; entretanto, segundo a observação participante da pesquisa, percebe-se que muitos ingressantes não conseguiram permanecer dentro do espaço acadêmico devido às suas responsabilidades para com os familiares do Haiti. Além de estudar, outros tiveram que trabalhar para poder ajudar com as despesas no país de origem.

\section{NA UNILA}

A Universidade Federal da Integração Latino-Americana (UNILA) começou a ser estruturada em 2007 pela Comissão de Implantação com a proposta de criação do Instituto Mercosul de Estudos Avançados (IMEA), em convênio com a Universidade Federal do Paraná (UFPR) e a Itaipu Binacional. A Comissão de Implantação da UNILA foi instituída pela SESu/MEC, por meio da Portaria n ${ }^{\circ} 43$ de 17 de janeiro de 2008, presidida por Hélgio Trindade, professor titular de Ciência Política, exreitor da UFRGS e membro da Câmara de Educação Superior do CNE. 
No dia 12 de dezembro de 2007, o ex-presidente Luiz Inácio Lula da Silva apresentou, ao Congresso Nacional, o projeto de lei que viria, mais tarde, a criar da Universidade Federal da Integração Latino-Americana, a UNILA. Como uma prova inconteste do interesse da sociedade em criar uma Universidade inovadora e voltada à integração latino-americana, o Projeto de Lei foi aprovado por unanimidade em todas as comissões por que passou, tanto na Câmara dos Deputados quanto no Senado Federal. E, finalmente, no dia 12 de janeiro de 2010, exatamente no mesmo dia em que ocorreu o terremoto que aniquilou o Haiti, a Lei 12.189 foi sancionada pelo presidente Lula, em cerimônia realizada em Brasília. A UNILA, instalada provisoriamente no Parque Tecnológico Itaipu (PTI), em Foz do Iguaçu, iniciou suas atividades acadêmicas ainda em 2010, no dia 16 de agosto. Na ocasião, a Universidade já tinha cerca de 200 alunos oriundos do Brasil, Paraguai, Uruguai e Argentina, subdivididos em seis cursos de graduação.

Um ano depois da UFFS, a Universidade Federal da Integração Latino-Americana seguiu o passo através do edital No 004/2014/ PROINT-UNILA, de 17 de dezembro de 2014. Em termos de requisitos para a candidatura, o sujeito tem que residir no Brasil sem ter a nacionalidade brasileira nem curso superior, deve ser maior de dezoito anos, e ter a nacionalidade haitiana, legalmente comprovada. No caso do campus de Chapecó da UFFS, a inscrição tem que ser feita na Secretaria Acadêmica; no caso da UNILA, ela deve ser efetuada online. Durante a mesma, o candidato deve imprimir, preencher corretamente todos os campos e assinar de próprio punho a ficha de Declaração, e uma cópia deve ser anexada ao formulário eletrônico (anteriormente preenchido) em formato PDF. Outros documentos, como registro nacional de estrangeiro, histórico escolar, declaração de conclusão do ensino médio e certidão de nascimento, também devem ser anexados.

Todos os estudantes matriculados no quadro do Programa estão Assistência Estudantil integral (alimentação, moradia, transporte) ofertada pela UNILA, de acordo com sua disponibilidade orçamentária ou em razão de bolsas ofertadas por outras instituições nacionais ou estrangeiras, sem prejuízo da possibilidade de concorrer às bolsas de iniciação científica, 
monitoria e extensão, de acordo com as regras e editais a serem publicados pela Universidade.

No dia da cerimônia que marcou a recepção dos Haitianos na UNILA, a pró-reitora da época, Gisle Ricobom, e o embaixador do Haiti, Madsen Chérubin, fizeram falas que contém as seguintes linhas, respectivamente:

A diferença desse programa em relação a outros é que a UNILA está concedendo a vaga e a assistência estudantil por reconhecer que esses estudantes não teriam condições de vir a Foz do Iguaçu sem apoio para que pudessem permanecer e concluir o curso(...). A UNILA está dando um passo importante e a gente espera que isso seja replicado em outras universidades.(...) Não podemos achar que eles são apenas uma força de trabalho, mas oferecer condições para que eles possam voltar ao Haiti e contribuir com seu país nas áreas nas quais serão formados.

Vejo de maneira muito positiva a iniciativa da UNILA e a busca de haitianos por melhores condições de vida. O importante é o acesso à educação. Acredito que se a oportunidade estiver presente, a pessoa pode mudar a sua situação.

Três haitianos que viviam em Cascavel iniciaram seus cursos na UNILA, no primeiro semestre de 2015. Para eles, estudar na UNILA significa uma oportunidade para melhorar de vida, seja no Brasil ou no Haiti. "Esperava uma oportunidade assim faz tempo. A gente tem que aproveitar para poder mudar nosso futuro e de nossas famílias", afirma Benile Esidor, estudante de Administração Pública e Políticas Públicas.

A mesma linha de pensamento tem Valando Lubérisse, que obteve uma vaga no curso de Biotecnologia. "O que a gente espera é que a gente se torne um profissional na carreira que escolheu. Se voltarmos para o Haiti, queremos ser os profissionais que o país esperava, chegar lá e dar o fruto do Brasil", disse. Ele está em Foz do Iguaçu com a irmã, Clerdine 
Lubérisse, que está fazendo Arquitetura e Urbanismo. "Estou feliz de fazer parte de uma universidade daqui", completou ela. Todos estão dispostos a se esforçar para conseguir seus objetivos. "Tenho certeza que $80 \%$ dos haitianos que conseguiram as vagas na UNILA vão estudar muito e vão tirar as melhores notas da faculdade", garante Valando.

Com tendência anual, no primeiro ano (2015), a UNILA selecionou 83 haitianos em diversos cursos. No ano seguinte, só 10 conseguiram entrar, enquanto havia um monte de inscritos. No ano de 2017, não houve processo seletivo, devido à situação econômica e política da universidade.

Segundo a lista de matrículas ativas de Haitianos liberada pela Pró-Reitoria de Relações Institucionais e Internacionais - PROINT, dos 93 (83 em 2015 e 10 em 2016) só restavam 62. As causas dessa evasão são profundas. Muitos abandonaram porque não conseguir conciliar estudo e trabalho - se é que existe trabalho para imigrante negro na região. Vale frisar também que muitos estudantes trancaram a matrícula para irem para outras universidades a fim de fazer outros cursos que buscavam.

\section{A PARTICIPAÇÃO DOS HAITIANOS NO ENSINO SUPERIOR}

No Brasil, segundo a legislação, o tripé formado pelo ensino, pela pesquisa e pela extensão constitui o eixo fundamental da Universidade e não pode ser secionado. O artigo 207 da Constituição Brasileira de 1988 dispõe que "as universidades [...] obedecerão ao princípio da indissociabilidade entre ensino, pesquisa e extensão". Equiparadas, essas funções básicas merecem igualdade em tratamento por parte das instituições de ensino superior, que, do contrário, violarão o preceito legal.

Como ressalta Silva (2000), as relações entre ensino, pesquisa e extensão decorrem dos conflitos em torno da definição da identidade e do papel da universidade ao longo da história. Assim, nas duas universidades estudadas percebe-se que além do ensino, a extensão e a pesquisa figuram no tecido acadêmico.

Ao entrar na universidade, os haitianos buscam uma forma de participar nesses três eixos fundamentais. Em relação à pesquisa e extensão, muitos deles participam como voluntários e/ou bolsistas. 
No ano passado (2016), participei como voluntário no projeto de extensão "Cine foto clube Ta'anga" cujo foco é de levar Oficinas de Fotografia nas comunidades. Paralelamente, desde Março de 2016, participo como membro de equipe e bolsista do projeto "RASANBLEMAN" (Primeira e segunda edição) Como tentativa de contribuir para o desenvolvimento de políticas de acolhimento linguísticas, culturais, sociais e acadêmicas para as comunidades migrantes haitianas, abrindo espaço de interação entre as culturas do Haiti e a sociedade brasileira... Também, desde 2016, faço parte da equipe dos projetos de pesquisa "LINGUAGENS, INTEGRAÇÃO E CULTURAS MIGRANTES: UNIVERSIDADE PÚBLICA E POLÍTICAS LINGUÍSTICAS" e "LINGUAGENS E CULTURAS MIGRANTES: UNIVERSIDADE PÚBLICA E POLÍTICAS DE ACOLHIMENTO” (UNILA, 2014, p. $5)$.

Participo num projeto de extensão cujo nome é UNILA FALA FRANCÊS. Este visa o ensino da língua francesa à comunidade acadêmica. É uma experiência muito agradável. Consigo compartilhar meu conhecimento (UNILA, 2014, p.11).

Eu participo como voluntário num projeto de pesquisa chamado "DESENVOLVIMENTO DE PORTAENXERTOS DO GÊNERO Prumus spp. PARA --PESSEGUEIROS, NECTARINEIRASEAMEIXEIRAS: REDE BRASILEIRA DE AVALIAÇÃO-UNIDADE DE OBSERVAÇÃO COM PORTA ENXERTOS CLONAIS NAS CONDIÇÕES EDAFOCLIMÁTICAS DE CHAPECÓ”. Um outro pelo qual sou responsável (bolsista) é "MELHORAMENTO GENÉTICO DE GOIABEIRA, AVALIAÇÃO DE GENÓTIPO X AMBIENTE, RESISTÊNCIA A DOENÇAS E FENOLOGIA DA FLORAÇÃO E FRUTIFICAÇÃO”. Inclusive em outros que estou ajudando meus colegas de pesquisa que não menciono aqui (UFFS, 2013, p. 3). 
Além de participar em atividades de extensão e pesquisa da Universidade, alguns deles conseguem fazer estágio.

Minha experiência no meio universitário está sendo bem. Pois, além de ter um índice de desempenho acadêmico razoável, consegui conciliar meus estudos com atividades extracurriculares, tanto para realizar estágios remunerados no campo do curso que estou realizando, como para integrar projetos de extensão e de iniciação científica da comunidade acadêmica da UNILA. No momento participo do projeto de extensão: curso de ensino de língua: " KreyòlAyisyen: kreyòlpale, kreyòlkonprann!”. Também, realizo estágio numa autarquia municipal chamada Foz Previdência (UNILA, 2014, p. 8).

Os que não estão participando em nenhum projeto de extensão ou pesquisa, devido à carga horária do curso ou pelo simples fato de serem calouros, pretendem fazer isso antes de terminar a graduação. Com ajuda de professores, alguns já estão escrevendo projetos.

Estou desenvolvendo um projeto da educação ambiental... um projeto que tem como objetivo de estudar no bresil o q fazia pra melhorar as situacoes ambientais e compatilha esses conhecimentos com meu povo pra poder melhorar também a nossa situação ambiental (UFFS, 2013, p. 4).

\section{CONSIDERAÇÕES FINAIS}

A busca das melhores condições de vida levou numerosos cidadãos haitianos a tentar suas chances fora da sua terra natal, seja em situações de migração irregular ou por emigração regular para outros países da região ou fora. A tomada em consideração dessas populações expatriadas, seja na sua integração em estratégias de desenvolvimento e reconstrução do país, seja pela sua reintegração em casos de retorno voluntário, é um dos principais impulsos de uma política de gestão de migração e desenvolvimento. 
$\mathrm{Na}$ ausência de uma política migratória clara, as leis internas em vigor sobre a migração arriscam produzir efeitos perversos, privilegiando a clandestinidade e a informalidade. A ausência de um quadro de direito internacional adequado representa também um desafio para o Haiti, apesar dos recentes esforços para estudar as implicações da adesão aos principais tratados sobre os direitos humanos dos migrantes.

Tanto a UFFS quanto a UNILA mencionaram nas suas resoluções que a inserção dos haitianos no ensino superior no Brasil é uma das formas cruciais para contribuir na reconstrução e no desenvolvimento do Haiti. No entanto, os Haitianos inseridos foram selecionados no Brasil e não no Haiti e sem a assinação de nenhum termo de compromisso garantindo a volta deles. Isto é, eles não vão ter a obrigação de voltar ao Haiti a fim de cumprir a missão. Depois deles se formarem, eles poderão optar por ficar no Brasil ou também ir para outros cantos do mundo.

Entretanto, segundo a pesquisa participante que foi feita, percebese que todos os participantes têm essa enorme vontade de ajudar o país de origem. Mesmo os que não voltarem à terra natal para morar definitivamente, vão, de certo modo, contribuir de longe.

\section{REFERÊNCIAS BIBLIOGRÁFICAS}

ALEXANDER, Leslie. "The Black Republic": The influence of the Haitian Revolution on Northern Black Political Consciousness. Routledge: New York and London, 2013.

BELLO, Beyyinah. Completing the Haitian Revolution of 1791. Disponível em: $<$ https: / $/$ www.youtube.com/watch?v=9bqPbq0NQtQ $>$. Acesso em: 03/08/2017.

BRASIL, MRE. Memorando de entendimento entre o Governo da República Federativa do Brasil e o Governo da República do Haiti para a reconstrução, o fortalecimento e a recomposição do Sistema de Educação Superior do Haiti, 2010. Disponível em: < http:/ / www. jusbrasil.com.br/diarios/1590414/pg-126-secao-1-diario-oficial-dauniao-doude- 30-03-2010>. Acesso em: 01/12/2015. 
BULMER-THOMAS, Victor. The wider Caribbean in the 20th Century: A long-run development perspective. In: Integration and Trade, v. 5, 2001.

CEOLIN, George. Crise do capital, precarização do trabalho e impactos no Serviço Social. Revista de Serviço Social, São Paulo, 2014.

RIBEIRO, Darcy. O Povo Brasileiro: a formação e o sentido do Brasil. Curitiba, 1995.

DIEME, Kassoum. Imigração Haitiana E Política De Acolhimento Institucional Na Cidade De São Paulo: 2010-2015. Dissertação (Mestrado em Sociologia). Instituto de Filosofia e Ciências Humanas, Universidade Estadual de Campinas, 2016.

FATTON, Robert. Haiti: Trapped in the Outer Periphery. Boulder: Lynne Reinner, 2014.

FOLHA. Vinda de haitianos é maior onda imigratória ao país em cem anos, 2012. Disponível em: < https://www1.folha.uol.com.br/ mundo/1033447-vinda-de-haitianos-e-maior-onda-imigratoria-aopais-em-cem-anos.shtml >. Acesso em: 03/07/2018.

HANDERSON, Joseph. Diáspora: Sentidos Sociais e Mobilidades Haitianas. Horizontes Antropológicos, Porto Alegre, n. 43, 2015.

HEADLEY, Bernard. The Jamaican crime scene: a perspective. Washington: Howard University Press, 1996.

LAURENT-COPA, Denis. Haïti: Une Colonie Française 1625-1802. Paris: Harmattan, 1993.

MARINO, Aline. Pró-haiti: reflexões sobre as ações afirmativas para haitianos nas universidades públicas brasileiras. Brasília, 2016.

OIM (ORGANISATION INTERNATIONALE POUR LES MIGRATIONS). Migration en haiti. profil migratoire national. Port au Prince: OIM, 2015. 
PETRAS, Elizabeth. Jamaican labor migration: white capital and black labor, 1850-1930. Boulder: Westview Press, 1988.

RICHARDSON, Bonham. Panama Money in Barbados, 1900-1920. Knoxville: University of Tennessee Press, 1985.

SEGUY, Franck. A catástrofe de janeiro de 2010, a "Internacional Comunitária" e a recolonização do Haiti. Dissertação (Doutorado em Sociologia). Instituto de Filosofia e Ciências Huamnas, Universidade Estadual de Campinas, 2014.

TOBIN, Kathleen. Population Density and Housing in Port-au-Prince. In: Historical Construction of Vulnerability Journal of Urban History, v. 39, 2013.

UNIVERSIDADE FEDERAL DA INTEGRAÇÃO LATINOAMERICANA. Conselho Universitário. Edital no 004/2014/ PROINT-UNILA, de 17 de dezembro de 2014.

UNIVERSIDADE FEDERAL DA INTEGRAÇÃO LATINOAMERICANA. Relatório do encontro do embaixador com um grupo que pesquisa a diáspora haitiana. Foz do Iguaçu, 2015. Disponível em: https://www.unila.edu.br/noticias/haiti-0

UNIVERSIDADE FEDERAL DA FRONTEIRA SUL. Conselho Universitário. Resolução no 32/2013 - CONSUNI.

VEGA, Bernardo. Trujillo y Haiti. Santo Domingo: Fundación Cultural Dominicana, 1988.

WARGNY, Christophe. Haïti n'existe pas 1804-2004: deux cents ans de solitude. Paris: Éditions Autrement Frontières, 2008. 
